DOI 10. 18307/2017. 0402

(c) 2017 by Journal of Lake Sciences

\title{
引水工程絮凝剂余铝对杭州西湖水体、底泥铝盐分布的影响”
}

\author{
张 玥 $^{1,2}$, 徐 栋 ${ }^{1 * *}$, 张 $义^{1}$, 刘碧云 ${ }^{1}$, 肖恩荣 ${ }^{1}$, 周巧红 ${ }^{1}$, 贺 锋 $^{1}$, 吴振斌 ${ }^{1}$ \\ (1:中国科学院水生生物研究所淡水生态与生物技术国家重点实验室,武汉 430072) \\ (2: 中国科学院大学, 北京 100049)
}

\begin{abstract}
摘 要: 通过对杭州西湖综合保护工程钱塘江引水范围内多个湖区水体和底泥中铝盐含量的调查分析, 研究了工程絮凝 剂余铝对西湖水体、底泥铝盐及沉水植物附着物的影响. 结果表明: (1)引水工程输人的絮凝剂残余铝盐导致各湖区人水 口水中铝离子含量普遍高于湖心, 高出 7.86\% 288.55\% 不等, 但底泥中 $\mathrm{Al}_{2} \mathrm{O}_{3}$ 含量在整个湖区分布较为均匀; (2) 约 $0.04 \sim 0.20 \mathrm{~m} / \mathrm{s}$ 流速下, 沉水植物很容易成为残余铝盐絮凝物的附着受体; (3) 秋、冬季水体中铝离子浓度较高, 对西湖水 生生物存在更大的生物潜在危害, 有必要重视秋、冬季的沉水植物恢复工作. 引水工程对西湖水体的影响是长久且难以 预见的, 在引水的同时应尽量减少其负面影响, 可减少絮凝剂的使用或选择环保型絮凝剂, 并选择合适的水生植物.
\end{abstract}

关键词: 西湖;引水工程;铝盐; 絮凝剂;底泥; 附着物

\section{Effects of residual aluminum flocculant on aluminum salt distribution of water and sediment in West Lake( Hangzhou)}

ZHANG Yue ${ }^{1,2}$, XU Dong ${ }^{1 * *}$, ZHANG Yi $^{1}$, LIU Biyun $^{1}$, XIAO Enrong ${ }^{1}$, ZHOU Qiaohong ${ }^{1}$, HE Feng $^{1}$ \& WU Zhenbin ${ }^{1}$

(1: State Key Laboratory of Freshwater Ecology and Biotechnology, Institute of Hydrobiology, Chinese Academy of Sciences, Wuhan 430072, P.R.China)

(2: University of Chinese Academy of Sciences, Beijing 100049, P.R.China)

\begin{abstract}
Aluminum salt content in the water body and sediment of Hangzhou West Lake was investigated to study the effects of residual aluminum flocculant on aluminum salt content of water, sediment and attachments on submerged macrophyte. The results show that: (1) Aluminum ion content of water inlets is higher than that of the central lake, which caused by residual aluminum flocculants from Diversion Project, while $\mathrm{Al}_{2} \mathrm{O}_{3}$ content of sediment tend to be distributed evenly across the lake and is not affected by the Diversion Project; (2) With the flow velocity of about 0.04 to $0.20 \mathrm{~m} / \mathrm{s}$, submerged macrophyte can easily become attachment receptors to residual aluminum flocculate, but is slightly weaker than sediment in the ability of attaching $\mathrm{Al}_{2} \mathrm{O}_{3}$ content; $(3$ ) Aluminum ion content of water is high in autumn and winter, which may potentially cause greater biological harm to aquatic organism in the lake. Therefore, it is important to restore submerged macrophyte in autumn and winter seasons. Effect of Diversion Project on the West Lake water body is essential but unpredictable. It should be possible to reduce the negative impact of Diversion Project. The use of flocculant can be reduced or environmentally friendly flocculant can be chosen instead, and appropriate aquatic plants may be cultivated near water inlets.
\end{abstract}

Keywords: West Lake; Diversion Project; aluminium; flocculant ; sediment; attachments

杭州西湖是典型的城市景观湖泊, 湖面被苏堤、白堤分成大湖、北里湖、岳湖、西里湖和小南湖 5 个湖 区, 各湖区水体借桥洞相通; 2003 年向西扩展之后, 增加了茅家埠、乌龟潭、浴鹄湾等子湖, 水域面积扩大到 $6.5 \mathrm{~km}^{2[1-2]}$. 随着城市化的进程和旅游业的发展, 西湖面临着严峻的富营养化及以生态系统退化为主要特征

* 国家自然科学基金项目 (51208498) 和国家水体污染控制与治理科技重大专项 (2012ZX07101007-005) 联合资助. 2016 - 06 - 20 收稿; 2016-10-25 收修改稿. 张玥(1990 ), 女, 硕士研究生;E-mail: lunezhang@ 126.com.

** 通信作者; E-mail:xudong@ ihb.ac.cn. 
的水质恶化问题 ${ }^{[3-4]}$. 为了改善这一情况, 当地采取了综合保护工程 ${ }^{[1,5-6]}$,包括疏浚清淤、引江济湖、面源污 染控制、西湖西进、生态修复等,使得西湖的水质和生态环境得到显著改善. 其中引钱塘江水置换西湖是较 快速改善西湖水质的方法, 但钱塘江水泥沙含量较大, 取水口潮汐变化造成水位变化较大, 江水浊度也有较 大的波动, 易对西湖造成二次污染. 为了解决这一问题, 人湖之前使用了铝盐絮凝剂对钱塘江水进行了混凝 沉淀处理,在置换西湖湖水的同时也输人了相当数量的预处理过程中残余的铝盐.

针对水体铝盐的研究主要聚焦在饮用水安全 ${ }^{[7-9]}$, 对地表水中铝盐的安全限值研究较少. 铝对鱼类等水 生生物也有一定的毒性, 主要取决于铝的价态、浓度以及水体的 $\mathrm{pH}$ 值与硬度 ${ }^{[10]}$. 目前, 地表水中的铝对水 体及水生物的影响还未受到重视, 尤其是针对微污染原水引水工程连续输人的铝盐, 对水体及整个生境的 影响, 相关研究还比较少. 引水工程对人水口附近湖床进行常年不断地冲刷, 会造成底泥的再悬浮, 促进了 沉水植物表面附着物的生成与大量累积,一方面影响了水生植物景观, 另一方面可能会对水生植物的生长 繁殖造成不良影响, 为进一步开展湖区水生植物定植及结构优化工作带来较大的困难和影响, 继而影响对 整个湖泊的富营养化控制进程. 本文以西湖引水工程影响区域中的乌龟潭、茅家埠、小南湖等湖区为研究对 象, 对残余絮凝铝盐在西湖水体、底泥的积累进行了初步解析, 旨在为湖泊富营养化治理提供科学的理论 依据.

\section{1 研究背景与方法}

\section{1 西湖引水工程概况}

杭州西湖钱塘江引水工程始建于 1985 年,2003 年引配水改建工程完成后, 玉皇山和赤山埠两座预处理 水厂的投产使用, 确保了西湖日引水量 $40 \times 10^{4} \mathrm{~m}^{3}$, 年引水量约达 $1.2 \times 10^{8} \mathrm{~m}^{3}$, 使西湖的换水周期缩短为 1 个 月 ${ }^{[11]}$. 其中玉皇山预处理厂日处理量 $30 \times 10^{4} \mathrm{~m}^{3}$, 使用絮凝剂为聚合氯化铝 $(\mathrm{PAC})$, 经人水口进人小南湖; 赤山埠水厂日处理量 $10 \times 10^{4} \mathrm{~m}^{3}$, 使用絮凝剂为明矾 $\left[\mathrm{KAl}\left(\mathrm{SO}_{4}\right)_{2}\right]$, 钱塘江原水经预处理后通过配水管经杨 公堤进人西湖西进水域 (茅家埠 $5 \times 10^{4} \mathrm{~m}^{3}$ 、乌龟潭 $3 \times 10^{4} \mathrm{~m}^{3}$ 、浴鹄湾 $2 \times 10^{4} \mathrm{~m}^{3}$ ), 再经由西里湖进人大湖和北 里湖, 共计 6 个人水口, 11 个出水口 ${ }^{[12]} .2$ 个水厂所用的絮凝剂均为液态, 在配药池进行稀释后经泉 $24 \mathrm{~h}$ 连 续不断输人水厂反应池, 在反应池混合均匀后进人沉淀池混凝沉淀, 流量主要根据出水浊度进行调节.

相对来说, 茅家埠、乌龟潭、浴鹄湾、小南湖有直接的引水人水口, 在本文中定义为直引水湖区; 大湖、西 里湖、北里湖没有引水管道, 定义为非直引水湖区.

\section{2 研究区域}

为研究引水工程絮凝余铝对西湖底泥铝盐及附着物的影响, 选取沉水植物附着现象最严重的乌龟潭, 沿引水流场路线设置了 3 个监测点 ( W1、W2、W3), 并在人水口附近采集了附着物. 根据引水口设置和线路 分布, 进一步在整个湖区确定了共 11 个监测位点, 图 1 为西湖各湖区平面分布及引水工程路线图 (箭头所 示), 图 2 为具体监测位点.

\section{3 采样与分析方法}

底泥采样: 利用柱状采样器采集监测位点表层 $10 \mathrm{~cm}$ 底泥, 每个采样点均经多点采样混合, 样品风干待 测. 沉水植物表面附着物用蒸馏水及软毛刷洗至烧杯中,过滤烘干待测.

底泥及附着物氧化铝 $\left(\mathrm{Al}_{2} \mathrm{O}_{3}\right)$ 、有机质含量等测定依据 JY/T 016-1996 波长色散型 X 射线苂光光谱仪 方法通则, 采用 Axios advanced X 射线苂光光谱仪对样品进行全元素分析. 底泥及附着物总氮 (TN) 含量采 用过硫酸钾消化法 ${ }^{[13]}$ 测定, 总磷 (TP) 含量采用碱熔-锄锑抗分光光度法 (HJ 632-2011) 测定. 底泥及附着 物采用 JSM-5610LV 扫描电子显微镜进行微观图像的采集处理. 水中流速采用 MGG/KL-DCB 型便携式电磁 流速仪测定. 水中铝离子浓度采用铬天青 S 分光光度法 ( GB/T 5750.6-2006) 测定. 数据采用 SPSS 13.0 软 件进行统计分析.

\section{2 结果与讨论}

\section{1 引水工程对乌龟潭底泥及附着物的影响}

$\mathrm{W} 1 、 \mathrm{~W} 2 、 \mathrm{~W} 3$ 为乌龟潭引水流线上的 3 个位点, 附着物也采自 W1 位点 (图 3). W1、W2 和 W3 位点底泥 


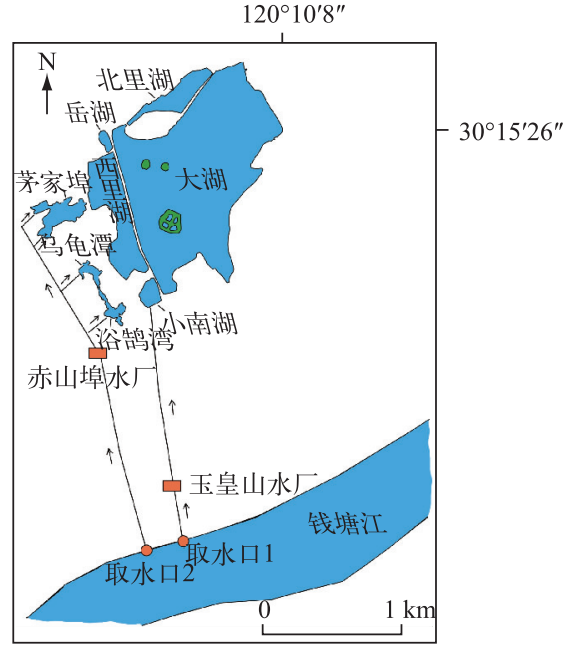

图 1 西湖平面及引水工程路线

Fig. 1 The ichnography of West Lake and the route of diversion project

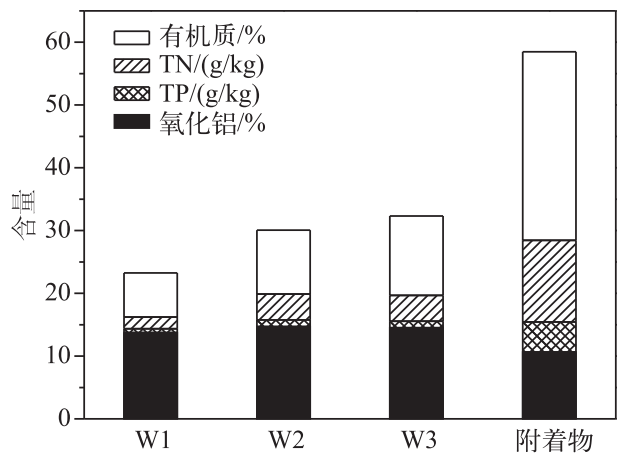

图 3 乌龟潭底泥、附着物 $\mathrm{Al}_{2} \mathrm{O}_{3}$ 、 TN 、TP 及有机质含量

Fig. $3 \mathrm{Al}_{2} \mathrm{O}_{3}$, TN, TP and organic matter contents of sediment and attachments of Turtle Pond

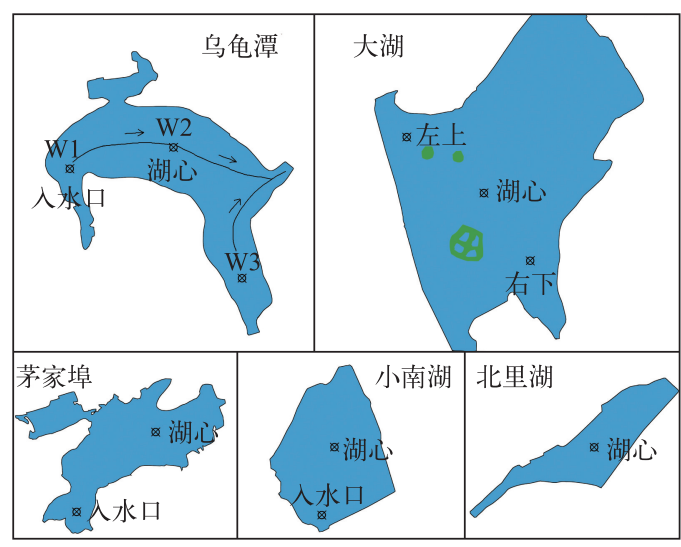

图 2 西湖各湖区监测位点

Fig.2 Monitoring sites of West Lake district

$\mathrm{Al}_{2} \mathrm{O}_{3}$ 含量分别为 $13.73 \% \pm 1.32 \% 、 14.69 \% \pm 1.10 \%$ 和 $14.50 \% \pm 0.81 \%$, 三者相差仅 $1.31 \% \sim 7.00 \%$, 较为接近, W1 作为最接近人水口的位点, $\mathrm{Al}_{2} \mathrm{O}_{3}$ 含量反而最低. 3 个位点 对应的 TP 含量分别为 $0.64 \pm 0.09 、 1.09 \pm 0.11$ 和 $1.05 \pm 0.30$ $\mathrm{g} / \mathrm{kg}$. TN 与 TP 含量变化趋势相似, 有机质含量呈上升趋 势, W1、W2、W3 位点逐渐升高. 附着物 $\mathrm{Al}_{2} \mathrm{O}_{3}$ 含量为 $10.64 \% \pm 0.56 \%$, 略低于底泥, 而 TN、TP 和有机质含量则 远高于底泥, 分别是底泥的 $2.15 \sim 6.98 、 2.32 \sim 7.48$ 和 $2.37 \sim 4.28$ 倍.

为了从微观形态探讨附着物来源及其与底泥的关 系, 对乌龟潭底泥和附着物进行了电镜扫描, 从微观形态 可以明显看出底泥为颗粒状, 粒径范围约 5 20 $\mu \mathrm{m}$, 而附 着物为薄层状和片状, 薄层厚度约为 $0.5 \mu \mathrm{m}$, 片状大小约 为 $1 \sim 300 \mathrm{\mu m}^{2}$, 且层片极少团聚, 各自成片 (图 4). 可见附 着物大多为絮凝剂的絮体与丝状藻、动植物残体等的结 合物, 与底泥不同, 其 $\mathrm{Al}_{2} \mathrm{O}_{3}$ 主要来源于悬浮絮体. 输人的 铝盐及絮体一部分停留在水中, 部分沉降至底泥, 另一部分则沉降附着于沉水植物表面或湖床卵石等物质 表面.

西湖底泥颗粒粒径有 $80.8 \%$ 处在 0.0029 0.067 mm 之间, 属粉砂级范围, 难以完全沉降. 而底泥本身是 最复杂的絮凝体, 其中的矿物微粒、粘土矿物、水合金属氧化物、腐殖质、有机质等相互作用, 通过各种凝聚 絮凝方式相互絮凝 ${ }^{[14]}$, 在游船的扰动、引水水流冲刷下极易再悬浮. 水中残留的絮凝剂会使分散在水中的 不能及时被絮凝下来的微小底泥及悬浮物颗粒在温度适宜、时间允许的情况下重新絮凝, 使微小的粒子聚 结成为较大的絮状物 ${ }^{[15]}$, 随水流沉降于附近的沉水植物表面,不断累积形成附着物.

在水流的作用下, 铝盐絮体及有机物质更容易被沉水植物拦截吸附, 而非沉降至湖底, 这也可能是人水 口底泥 $\mathrm{Al}_{2} \mathrm{O}_{3}$ 含量最低的原因之一. 在乌龟潭人水口附近测定了水流流速, 发现距离人水口约 $5 \mathrm{~m}$ 处, 流速 可达 $0.21 \mathrm{~m} / \mathrm{s}$; 距离约 $30 \mathrm{~m}$ 处, 流速约为 $0.20 \mathrm{~m} / \mathrm{s}$; 距离约 $55 \mathrm{~m}$ 时, 流速降到 $0.08 \mathrm{~m} / \mathrm{s}$; 距离约 $80 \mathrm{~m}$ 时, 流速 

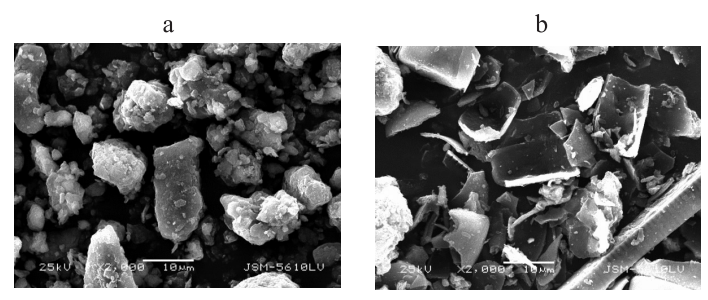

图 4 乌龟潭底泥 (a) 和附着物 (b) 电镜图像

Fig.4 Electron microscopy images of sediment(a) and attachments(b) of Turtle Pond

仅 $0.04 \mathrm{~m} / \mathrm{s}$; 距离人水口约 $100 \mathrm{~m}$ 时, 水面已近于静水状态. 人水口附近流速较大, 悬浮物及漂浮物不易沉降 附着, 随流速递减, 悬浮物及漂浮物更易沉降及被拦截, 故底泥有机质随流速呈上升趋势. 底泥 $\mathrm{Al}_{2} \mathrm{O}_{3}$ 含量与 $\mathrm{TP}$ 含量呈正相关关系 (Pearson 相关系数为 0.995 ). 铝盐进人水体后, 铝离子与磷酸盐混合反应后通过化学 沉析作用去除部分磷, 经过这一系列的反应生成絮状体, 絮体的吸附作用可进一步去除部分磷 ${ }^{[16]}$, 使水体中 磷含量得到一定程度的降低, 同时铝盐作为钝化剂在底泥表层形成的隔离层对磷也有一定的吸附作用, 能 有效削减底泥释放的污染物进人水体, 从而达到控制磷释放的目的 ${ }^{[17]}$.

附着物有机质含量远高于底泥, 可见沉水植物除对无机物质的拦截吸附之外, 更容易成为丝状藻、动植 物残体、着生藻等有机物质的附着受体. 在水流的作用下, N、P 含量丰富的物质(植物等) 可能更易于聚集附 着, 而不是沉降, 这是附着物 TN、TP 含量高于底泥的主要原因. 附着物对沉水植物的负面影响是不容忽视 的, 铝盐絮体会被隐藏在植物表面增加的有机物质中, 可能会影响到植株对营养盐的利用 ${ }^{[18]}$; 其次物理包裹 也会影响植物的光合、呼吸等生理作用; 另外, 过多的铝盐絮体也会对植株有一定的毒害作用, 影响植物正 常的生长代谢 ${ }^{[19]}$.

\section{2 引水工程对各湖区底泥铝盐、有机质含量的影响}

在全湖范围主要的引水湖区采集了底泥, 图 5 为不同湖区底泥 $\mathrm{Al}_{2} \mathrm{O}_{3}$ 及有机质含量, 其中乌龟 潭、茅家埠、小南湖湖区取的是人水口附近的底 泥,其他湖区均为湖心,水厂污泥采集的是玉皇山 预处理厂沉淀池污泥. $\mathrm{Al}_{2} \mathrm{O}_{3}$ 作为絮凝剂的有效成 分, 其含量一定程度上表征了絮凝剂输人对各湖 区的影响. 水厂污泥经过了絮凝沉淀, $\mathrm{Al}_{2} \mathrm{O}_{3}$ 含量 最高, 达 $18.6 \% \pm 1.25 \%$; 大湖左上和乌龟潭人水 口相近, $\mathrm{Al}_{2} \mathrm{O}_{3}$ 含量分别为 $14.55 \% \pm 0.97 \%$ 和 $14.2 \% \pm 2.03 \%$; 大湖右下及茅家埠人水口略低于 乌龟潭, 分别为 $13.86 \% \pm 0.54 \% 、 13.29 \% \pm 1.21 \%$; 北里湖湖心次之, 为 $12.7 \% \pm 2.07 \%$; 大湖湖心和 小南湖人水口最低, 分别为 $11.03 \% \pm 0.56 \%$ 和

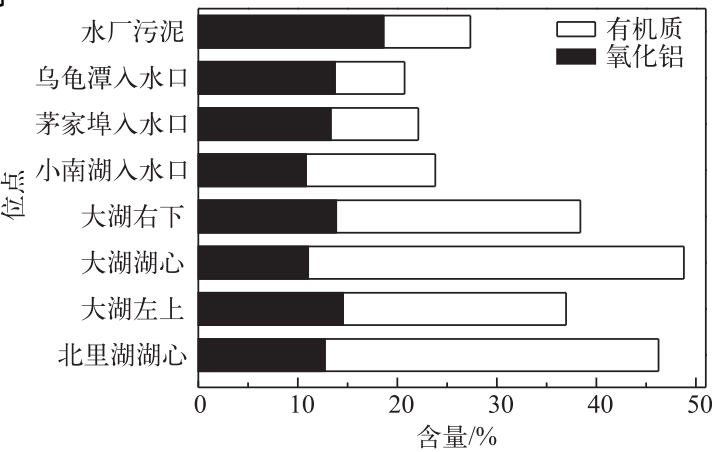

图 5 不同湖区底泥 $\mathrm{Al}_{2} \mathrm{O}_{3}$ 及有机质含量

Fig. $5 \mathrm{Al}_{2} \mathrm{O}_{3}$ and organic matter content of different lake sediments $10.8 \% \pm 1.07 \%$.

西湖引水的流场可见,直引水区人水口底泥 $\mathrm{Al}_{2} \mathrm{O}_{3}$ 含量没有高于相对影响较小的非直引水区, 整体来看趋 于均匀分布 (图 6). 可能长期的动态交换使得水泥两相铝盐达到一定的平衡, 而且湖区面积较小, 更利于离子 交换. 小南湖由于水体推移扩散效果最好 ${ }^{[12]}$ 而更容易扩散分布, 且换水频率最高反而不易沉积. 另外, 底泥中 $\mathrm{Al}_{2} \mathrm{O}_{3}$ 含量的均匀分布与沉水植物的分布也有一定关联. 人水口一般靠近湖岸, 水深小于湖心, 更适于沉水植 物的生长 ${ }^{[20]}$, 人水口附近生物量会大于湖心深水处, 而沉水植物的吸收利用或富集可能是人水口附近 $\mathrm{Al}_{2} \mathrm{O}_{3}$ 含 量没有显著高于湖心的因素之一. 有机质主要是水生动植物残渣、藻类及其分泌物等, 其变化趋势是非直引水 湖区大于直引水湖区. 直引水湖区有机物质在水中铝盐微小絮体及水流影响下更容易附着于沉水植物, 而非 沉降至湖底,并且沉水植物在被一层附着物包裹之后, 吸附、拦截能力增强,更容易造成进一步的附着. 


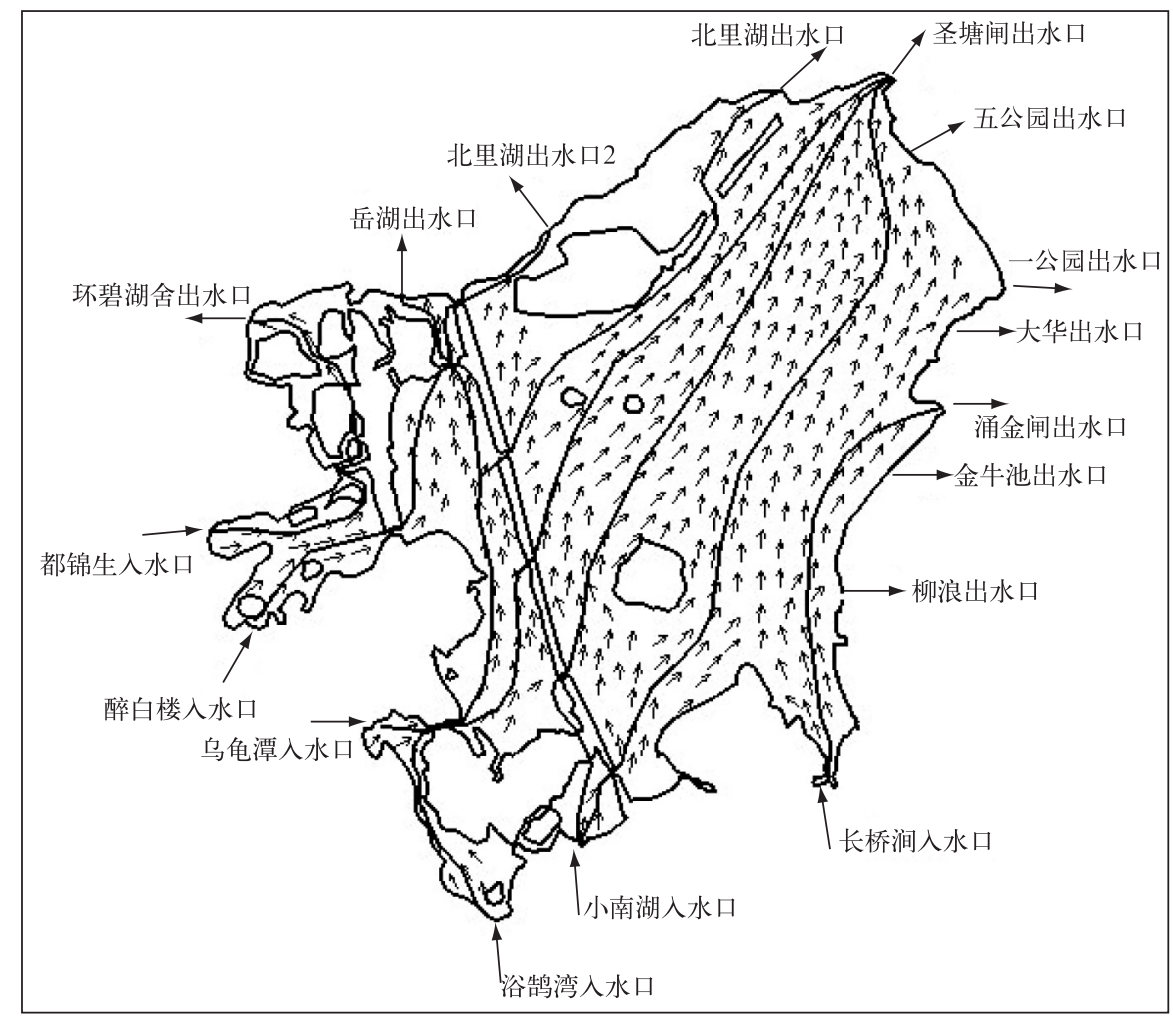

图 6 西湖流场及人水口、出水口详细分布 ${ }^{[12]}$

Fig.6 The flow field of West Lake and distribution of water inlets and outlets

\section{3 引水工程对各湖区水中铝盐浓度的影响}

首先对玉皇山、赤山埠 2 个预处理水厂的进出水进行了监测, 以确定西湖引水工程铝盐的来源背景值. 2 个水厂进水浊度有一定变化, 变化幅度较大, 玉皇山水厂进水浊度变化范围为 $20 \sim 110 \mathrm{NTU}$, 赤山埠水厂则 为 $20 \sim 40 \mathrm{NTU}$, 但二者出水浊度都比较稳定, 约 $1.5 \pm 1.5 \mathrm{NTU} ; 2$ 个水厂出水铝离子浓度有所不同, 玉皇山约 为 $250 \pm 50 \mu \mathrm{g} / \mathrm{L}$, 赤山埠约为 $150 \pm 50 \mu \mathrm{g} / \mathrm{L}$, 浓度都比较稳定. 水厂的运行主要以出水浊度为标准, 出水浊度 略小于西湖平均浊度 (约 $4.00 \mathrm{NTU}$ ).

2013 年 10 月至 2014 年 9 月西湖主要几个引水湖区人水口的铝离子浓度普遍高于湖心, 高出 $7.86 \%$ $288.55 \%$ 不等,与同一时段水厂出水铝离子浓度接近; 而 2014 年 1 月 14 日采样这天 (图 7a 中红色点) 由于 水厂停水, 没有进水, 当天的湖心和人水口铝离子浓度都很低, 差距也很小 $(7.86 \% \sim 24.85 \%)$, 之后引水暂停 时也有类似趋势. 秋、冬季 (10-4 月) 铝离子浓度较高, 约 $170 \pm 75 \mu \mathrm{g} / \mathrm{L}$, 春、夏季 $(5-9$ 月) 铝离子浓度较 低, 约 $60 \pm 25 \mu \mathrm{g} / \mathrm{L}$. 同样的时间, 不同湖区湖心的铝离子浓度差异较大, 小南湖高于茅家埠、乌龟潭高于北里 湖、西里湖; 而各湖区人水口的铝离子浓度差异较小,乌龟潭高于小南湖高于茅家淖( 图 7a).

人水口铝离子浓度普遍高于湖心, 可见引水工程带来的残余絮凝剂对西湖湖水中的铝盐浓度是有直接 影响的. 由于西湖换水频率高并且连续输人,换水过程中没有均匀扩散,铝盐聚集于人水口尚未扩散又不断 接受新输人的铝盐, 形成了一定的动态平衡, 始终高于湖心. 人水口铝盐浓度以乌龟潭最高, 其人水口处于 狭长的一端, 底部多卵石, 更不易扩散, 细小的絮体与再悬浮的轻质底泥由于水流作用不易沉降, 而是被沉 水植物拦截, 现场乌龟潭的沉水植物附着情况最为严重, 二者有一定的相关性.

西湖主要几个引水湖区湖心和人水口水中 $\mathrm{pH}$ 的在线测定结果, 与铝离子浓度监测的位点和时间一致. 总体来说, 各湖区湖心和人水口的 $\mathrm{pH}$ 处于中性偏碱, 湖心和人水口 2014 年 4-9 月的 $\mathrm{pH}$ 与 2013 年 10 月一 
2014 年 3 月相比均有下降趋势, 但下降幅度很小 (图 7b). 对铝离子浓度、对应水中 $\mathrm{pH}$ 、 TP 浓度及底泥 TP 含量进行 Pearson 相关性分析, 铝离子浓度与水中 $\mathrm{pH} 、 \mathrm{TP}$ 浓度均呈极显著正相关 $(P<0.01)$ (表 1$)$, 可见铝 离子的输人对湖水 $\mathrm{pH} 、 \mathrm{TP}$ 浓度的变化有一定影响. 铝离子与水中悬浮物等形成的 $\mathrm{Al}(\mathrm{OH})_{3}$ 絮体具有很大 的比表面积, 对非溶解态的磷和磷酸盐沉淀物质有一定的吸附能力, 能将其吸附后共同沉淀下来 ${ }^{[21]}$. 水中 铝离子浓度与底泥 TP 含量呈负相关, 底泥中 $\mathrm{Al}_{2} \mathrm{O}_{3}$ 抑制了沉积物磷的释放, 从而降低了底泥 $\mathrm{TP}$ 含量和 $\mathrm{Al}$ 在水中的分配.

- 湖心 。入水口
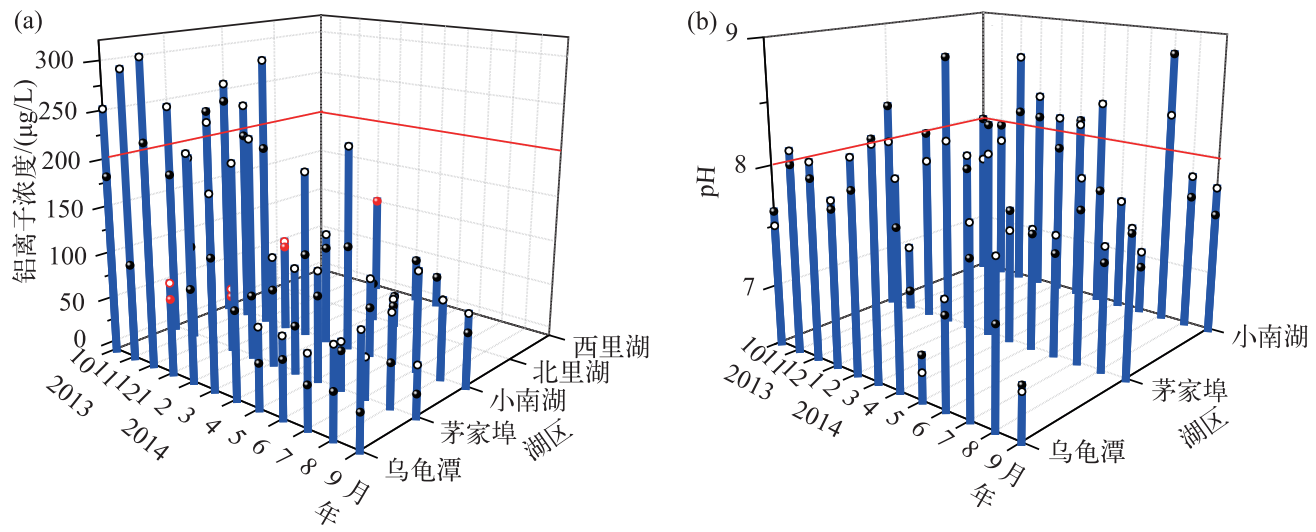

图 7 西湖不同湖区水中铝离子浓度 $(\mathrm{a})$ 和 $\mathrm{pH}(\mathrm{b})$ 时空分布

(a 图中红色实心小圆圈代表 2014 年 1 月 14 日,水厂停水,没有进水)

Fig.7 Aluminium ion concentration(a) and $\mathrm{pH}(\mathrm{b})$ of West Lake water at different time and space distribution

2013 年 10 月到 2014 年 9 月, 4 个引水 湖区人水口的铝离子浓度有 $31.25 \%$ 超过了 $200 \mu \mathrm{g} / \mathrm{L}$, 超过了《生活饮用水卫生标准》 ( GB 5749-2006) 的铝浓度限值 $(0.2 \mathrm{mg} / \mathrm{L})$. 有文献报道 ${ }^{[22]}$, 水中铝浓度高于 $200 \sim 500$ $\mu \mathrm{g} / \mathrm{L}$ 时, 即可使鲑鱼致死; $\mathrm{pH}$ 在 $8 \sim 9$ 的弱 碱性条件下, 水中的铝酸根离子浓度高于 $500 \mu \mathrm{g} / \mathrm{L}$ 时, 也可使䱦鱼致死. Driscoll 等 ${ }^{[23]}$ 研究发现当水中铝离子浓度高于 2 $\mu \mathrm{mol} / \mathrm{L}$ (即 $54 \mu \mathrm{g} / \mathrm{L}$ ) 时, 对鱼类有潜在毒 性. 虽然水中铝对鱼类影响的研究受到了最 多的关注, 但其对整个食物网的影响也通常 是负面的, 这一点不可忽视 ${ }^{[24]}$. 铝盐在 $\mathrm{pH}$ 约 6.0 8.0 时, 溶解度最小, 产生危害的可能也最小, 当 $\mathrm{pH}<5.5$ 或 $\mathrm{pH}>8.0$ 时, 铝盐可能从底泥中释放至水 中 $^{[25]}$, 西湖各湖区全年 $\mathrm{pH}$ 有 $28.13 \%$ 高于 8.0 , 最高达 8.80 , 其中 $91.3 \%$ 发生在 $10-3$ 月的秋冬季节, 对铝盐 从底泥的可能释放值得警示.

西湖各湖区铝离子的浓度已达到对水体中的鱼类产生潜在毒性的高度. 2013 年 10 月至 2014 年 4 月, 各湖区铝离子含量有 $53.57 \%$ 超过了 $200 \mu \mathrm{g} / \mathrm{L}$, 可见秋冬季节絮凝剂更易残留, 春、夏季温度较高, 可能由于 水温升高有利于絮凝, 使絮凝剂得到充分利用, 铝离子的残留量较少 ${ }^{[26]}$, 并且春、夏季藻类大量繁殖, 降低了 水中的磷浓度 ${ }^{[27]}$, 磷结合吸附的铝也有所减少. 目前从西湖各湖区的铝离子浓度来看, 秋、冬季对湖里的水 生生物有更大的潜在危害. 沉水植物对水中有害物质有一定的耐受性和适应性, 并且能大量吸附拦截絮凝 剂絮体, 这对整个湖泊潜在毒害的消减有一定作用, 秋、冬季开展沉水植物恢复是很有必要的. 


\section{3 结论}

1) 西湖引水工程输人的絮凝剂残余铝盐导致各湖区人水口水中铝离子浓度普遍高于湖心, 其中乌龟潭人 水口铝离子浓度可高达 $308.98 \mu \mathrm{g} / \mathrm{L}$, 对人水口沉水植物的附着有一定贡献; 引水残余铝盐絮凝剂的长期输人 及湖区面积较小使得底泥中 $\mathrm{Al}_{2} \mathrm{O}_{3}$ 含量在整个湖区趋于均匀分布, 未受流场明显影响. 可见引水工程输人的余 铝对西湖水体有一定影响, 建议在预处理时尽量减少絮凝剂的投加, 以避免过量,或者选用环保型絮凝剂.

2) 约 0.04 0.20 m/s 流速下, 沉水植物很容易成为附着受体, 残余絮凝剂铝盐对附着有促进作用, 有机 物质在流速及铝盐絮体参与下更容易附着于沉水植物, 而非沉降. 附着物 $\mathrm{Al}_{2} \mathrm{O}_{3}$ 更多来源于悬浮絮体及其与 丝状藻、动植物残体等的结合物, 而非底泥矿物颗粒;附着物有机质、TN 含量、TP 含量均高于底泥.

3) 秋、冬季水体中铝离子含量较高, 对西湖水生生物存在更大的潜在危害, 有必要重视秋、冬季的沉水 植物恢复工作. 另外, 人水口附近应尽量种植根系发达的挺水植物, 可搭配种植苦草、蕰草等条状叶形、生命 力强的沉水植物品种, 能减少附着物的附着累积,减少其对沉水植物生长的影响.

致谢: 感谢杭州西湖水域管理处、杭州西湖风景名胜区环境监测站、国家水专项西湖课题西湖工作站的谭 谈、萄庆伟、孙健、闵奋力等同学在样品采集、处理等方面提供的帮助与支持.

\section{4 参考文献}

[ 1 ] Deng Kaiyu, Wu Zhiying, Zhang Guoliang et al. Benifits of the restoration projects on West Lake: Evidence of chlorophyll-a change (1998-2007). J Lake Sci, 2009, 21(4) : 518-522. DOI: 10.18307/2009.0410. [ 邓开宇, 吴芝瑛, 张国亮. 从叶 绿素 a 的变化浅析西湖综合保护工程效益(1998-2007 年). 湖泊科学, 2009, 21(4): 518-522.]

[ 2 ] Yang Jun, Wu Zhiying, Xu Jun et al. Analysis of the nutrient characteristics and eutrophication status in different areas of West Lake. Environmental Science Survey, 2014, 33(3): 8-12. [杨俊, 吴芝瑛, 徐骏等. 西湖不同湖区营养盐特征及 富营养化现状研究. 环境科学导刊, 2014, 33(3): 8-12.]

[ 3 ] Liu Jingyu, Mao Faxin, He Shaoqi. Characteristics and an overall assessment of the aqueous quality of the West Lake Hangzhou. Journal of Hangzhou University, 1981, 8(3) : 309-319. [刘经雨, 毛发新, 何绍箕. 杭州西湖水质特征及其综 合评价. 杭州大学学报, 1981, 8(3): 309-319.]

[ 4 ] Wu Jie, Yu Zuoming. The succession of phytoplankton and the ecological effects of eutrophication control measures in Hangzhou West Lake. China Environmental Science, 2001, 21(6): 540-544. [ 吴洁, 虞左明. 西湖浮游植物的演替及富营 养化治理措施的生态效应. 中国环境科学, 2001, 21(6) : 540-544.]

[ 5 ] Lin Fengmei, Ye Xuhong, Jiao Li et al. Effects of comprehensive protection project to the ecological environment of West Lake in Hangzhou. Journal of Water Resources \& Water Engineering, 2007, 18(6): 1-4. [林丰妹, 叶旭红, 焦荔等. 综 合保护工程对杭州西湖生态环境的影响. 水资源与水工程学报, 2007, 18(6): 1-4.]

[6 ] Wu Zhiying, Wu Jie, Yu Zuoming. The reconstruction of aouatic macrophyte and ecological restoration in the West Lake. Environmental Pollution and Control, 2005, 27(1) : 36-40. [ 吴芝瑛, 吴洁, 虞左明. 杭州西湖水生高等植物的恢复 与水生生态修复. 环境污染与防治, 2005, 27(1): 36-40.]

[ 7 ] Flaten TP. Aluminium as a risk factor in Alzheimer's disease, with emphasis on drinking water. Brain Research Bulletin, 2001, 55: 187-196. DOI: 10.1016/S0361-9230(01)00459-2.

[ 8 ] Wang W, Yang H, Wang X et al. Factors effecting aluminum speciation in drinking water by laboratory research. Journal of Environmental Sciences, 2010, 22: 47-55. DOI: 10.1016/S1001-0742(09)60073-5.

[ 9 ] Wang Yanshan, Yan Youbin, Zhang Honglin. Main problems existed in drinking water in China and the solutions. Industrial Safety and Environmental Protection, 2005, 31(4): 17-19. [王晏山, 颜西斌, 张洪林. 我国饮用水中存在的主 要问题及解决方法. 工业安全与环保, 2005, 31(4) : 17-19.]

[10] Gao Xiuqing. Effects of residual aluminium in drinking water on water sanitary quality and its potential risk. Journal of Environment and Health, 2000, 17(6):381-383. [高秀清. 水中残留铝对水质的影响及其监测必要性. 环境与健康杂 志, $2000,17(6): 381-383$.

[11] CPPCC Hangzhou, Zhejiang. Carrying out the comprehensive management and protection project, to make the West Lake harmonious between man and nature. In: Population Resources and Environment Committee of CPPCC Jiangxi Province eds. Inland lakes and Poyang Lake Symposium on Sustainable Development. 2005: 61-63. [ 浙江省杭州市政协. 实施综 
合治理和保护工程打造人与自然和谐发展的新西湖. 见: 江西省政协人口资源环境委员会编. 内陆湖泊暨鄱阳湖 可持续发展研讨会论文集. 2005: 61-63.]

[12] Li Hongxian. Study on Numerical Simulation of the flow field and concentration field on the response to Weat Lake Water Diversion Project [Dissertation]. Hangzhou: Zhejiang University, 2006. [李红仙. 西湖流场和浓度场对引水工程响应 的数值模拟研究 [ 学位论文]. 杭州: 浙江大学, 2006.]

[13] Qian Junlong, Zhang Liandi, Le Meilin. Determination of soil total nitrogen and total phosphorus by persulfate digestion. Soil, 1990, 22(5) : 258-262. [ 钱君龙, 张连弟, 乐美麟. 过硫酸盐消化法测定土壤全氮全磷. 土壤, 1990, 22( 5) : 258-262.]

[14] Li Zhenyu, Zhu Yinmei, Wang Jin. Some physical and chemical characteristics of sediment in West Lake, Hangzhou. J Lake Sci , 1998, 10 (1) : 79-84. DOI : 10.18307/1998.0113. [李震宇, 朱荫湄, 王进. 杭州西湖沉积物的若干物理和 化学性状. 湖泊科学, 1998, 10(1): 79-84.]

[15] Zhu Lina, Liu Xiangchen, Jiang Tingting et al. Research on the suspended solids in the reinjection water of Daqing Oilfield. Chemical Engineer, 2013, 210(3) : 36-38. [ 朱丽娜, 刘祥臣, 姜婷婷等. 大庆油田回注水中悬浮物组成和成 因研究. 化学工程师, $2013,210(3): 36-38$. ]

[16] Cooke GD, Heath RT, Kennedy RH et al. Change in lake trophic state and internal phosphorus release after aluminum sulfate application 1. Jawra Journal of the American Water Resources Association, 1982, 18(4) : 699-705. DOI: 10.1111/j. 1752-1688.1982. tb00054.x.

[17] Zheng Miaozhuang. Effect of inactivation agent on the phosphorus release from sediment of Lake Dianchi and physiological activities of Myriophyllum spicatum [Dissertation]. Guangzhou: South China Agricultural University, 2008. [郑苗壮. 铝盐 对滇池底泥磷释放和狐尾藻生理活性的影响 [学位论文]. 广州: 华南农业大学, 2008.]

[18] Malecki-Brown LM, White JR, Brix H. Alum application to improve water quality in a municipal wastewater treatment wetland: Effects on macrophyte growth and nutrient uptake. Chemosphere, 2010, 79(2):186-92. DOI: 10.1016/j. chemosphere.2010.02.006.

[19] Kong Fanxiang, Sang Weilian, Jiang Xin et al. Aluminum toxicity and tolerance in plants. Acta Ecologica Sinica, 2000, 20(5): 855-862. [孔繁翔, 桑伟莲, 蒋新等. 铝对植物毒害及植物抗铝作用机理. 生态学报, 2000, 20(5): 855-862.]

[20] Liu Yong, Guo Huaicheng, Zhou Feng et al. Role of water level fluctuation on aquatic vegetation in lakes. Acta Ecologica Sinica, 2006, 26(9) : 3117-3126. [刘永, 郭怀成, 周丰等. 湖泊水位变动对水生植被的影响机理及其调控方法. 生态学报, 2006, 26(9): 3117-3126.]

[21] Wang Ting, Wang Sanfan. Analysis on the coagulant for phosphorus removal in different wastewater. Industrial Safety and Environmental Protection, 2008, 34(11): 7-9. [王挺, 王三反. 混凝剂对去除不同水质污水中磷的效果分析. 工业 安全与环保, 2008, 34(11): 7-9.]

[22] AWWA Sludge Disposal Committe Report. Research needs for alum sludge discharge. Journal of American Water Work Association, 1978: 99.

[23] Driscoll CT, Lawrence GB, Bulger AJ et al. Acidic deposition in the Northeastern United States: Sources and inputs, ecosystem effects, and management strategies. BioScience, 2001, 51 (3) : 180-198. DOI: 10.1641/0006-3568 ( 2001 ) 051 [0180: aditnu $] 2.0 . \mathrm{CO} ; 2$.

[24] Schindler DW, Mills KH, Malley DF et al. Long-term ecosystem stress: The effects of years of experimental acidification on a small lake. Science, 1985, 228: 1395-1401. DOI: 10.1126/science.228.4706.1395.

[25] Driscoll CT, Lee A, Montesdeoca M et al. Mobilization and toxicity potential of aminum from alum floc deposits in Kensico Reservoir, New York. Journal of the American Water Resources Association, 2014, 50 (1) : 143-152. DOI: 10.1111/ jawr.12122.

[26] Cui Fuyi, Hu Mingcheng, Zhang Yan et al. Investigation on aluminum concentration in drinking water in part of China's cities. China Water and Wastewater, 2002, 18(1): 5-8. [ 崔福义, 胡明成, 张燕等. 我国部分城市饮用水中铝含量调 查. 中国给水排水, $2002,18(1): 5-8$.

[27] Lu Shaoyong, Jin Xiangcan, Guo Jianning et al. Variation of nitrogen and phosphorus cncentration in water-sediment system and influence of overlying water on the algae growth. Environmental Science, 2007, 28(10): 2169-2173. [卢少勇, 金相灿, 郭建宁等. 沉积物-水系统中氮磷变化与上覆水对藻类生长的影响. 环境科学, 2007, 28 (10): 2169-2173.] 